\title{
A study of visual temporal size contrast'
}

HARRY HELSON ${ }^{2}$ AND TAKASHI KOZAKI ${ }^{3}$

YORK UNIVERSITY

Stimuli exposed successively with an interpolated larger or smaller stimulus (IS) are subject to size-contrast effects to a highly significant degree. While stimuli nearer IS are, in general, more affected than stimuli farther away, there is some indication of paradoxical distance effect (PDE): Stimuli somewhat farther from IS are more affected than those nearest IS. Intermediate IS has a splitting effect in that stimuli above are judged larger, and those below are judged smaller, thus verifying the results with IS below and above the series stimuli. The relation of these results to figural aftereffects is stressed.

While there are many studies of simultaneous contrast, particularly in the field of color and luminance contrast, there are few, if any, studies of successive or temporal contrast as pointed out by Flock, Wilson, and Poizner (1966). So far as we are aware there are no studies of successive size contrast unless figural aftereffects and certain adaptation-level phenomena are regarded as synonymous with contrast effects resulting from preceding stimulation. In the experiment reported here a visual stimulus was compared with itself following an interpolated stimulus (IS) using the method of constant stimulus differences. By using interpolated stimuli smaller than, in the center of, and larger than the series stimuli, the results for one condition are checked by the other two conditions, for with small IS there should be a majority of "larger" reports, with large IS there should be a majority of "smaller" reports, and with intermediate IS there should be a splitting effect if contrast is operative.

\section{Subjects}

\section{METHOD}

Seven Ss, five from the introductory course in psychology and two from the staff of laboratory technicians, participated in the three conditions of the experiment. All were naive so far as the purposes and design of the experiment were concerned. They were instructed as follows:

"This is an experiment on discrimination of size of squares. You will be shown three stimuli, successively. Report the size of the third stimulus with respect to the first one. You may report that the third stimulus is larger, equal, or smaller than the first. Use "equal' very sparingly."

\section{Apparatus and Procedure}

The apparatus was essentially the same as that employed in a previous study (Helson \& Kozaki, 1968) but with two additional Hunter timers necessitated by having three stimuli exposed successively instead of two. Light from gas-filled grids to provide even, white light illuminated milk glass screens from behind. Mounted in front of the milk glass screens were plastic transparent sheets painted matt black except for an area left clear to provide "white" squares against dark backgrounds. The squares were $36,45,54,63$, and $72 \mathrm{~mm}$ on a side and these served as the series or judged stimuli. The interpolated stimuli or anchors were 18,54 , or $90 \mathrm{~mm}$ on a side. A small red cross, actuated by a solenoid to move out of the field when the first stimulus was exposed, served as fixation point.

The order of stimulation was as follows: Series stimulus exposed for $1.0 \mathrm{sec}$, followed by IS after $0.5 \mathrm{sec}$ for $1.0 \mathrm{sec}$, followed by the first stimulus for $1.0 \mathrm{sec}$ after $0.50 \mathrm{sec}$ interval. Thus the stimuli were exposed for $1.0 \mathrm{sec}$ with $0.50 \mathrm{sec}$ interval between. That the interstimulus interval (ISI) is important was shown by the fact that Ss failed to give reliable judgments when ISI was $1.50 \mathrm{sec}$ instead of $0.50 \mathrm{sec}$.

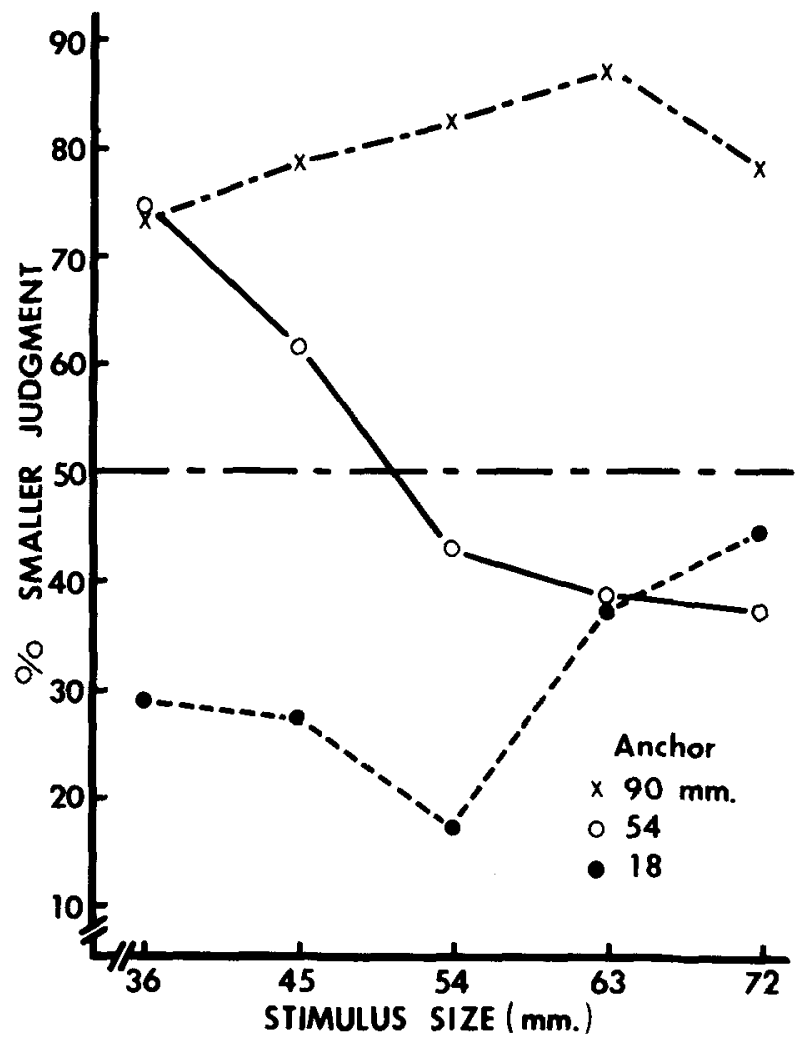

Fig. 1. Size contrast shown by per cent smaller judgments with anchors below, at the center, and above the series stimuli.

Apparently the 1.50 -sec interval between stimuli made the total time between the onset of the first stimulus and the third stimulus too long so that comparisons were very difficult for the Ss. Use of $0.50-\mathrm{sec}$ ISI gave very consistent, reliable results. The first stimulus served as standard with respect to which the third was compared. Each series stimulus was thus compared with itself with IS serving as the contrast-inducing stimulus.

Stimuli were presented in random order to all Ss. After one presentation of each stimulus under each of the three IS conditions for practice, the stimuli were judged a total of five times each, making 525 judgments in all ( 7 Ss $\times 5$ stimuli $\times 3$ interpolated stimuli $x 5$ replications). The interpolated stimulus is referred to as an anchor rather than as a standard because it was not directly involved in the comparisons.

\section{RESULTS}

The data of this experiment are given in Table 1 and are graphically illustrated for the "smaller" category judgments in Fig. 1. "Equal" judgments were divided between "larger" and "smaller" judgments. From both Table 1 and Fig. 1 it is seen that temporal contrast effects are large and statistical analysis shows they are also highly significant. With IS of $54 \mathrm{~mm}$, which was also the middle stimulus of the series, the two smaller stimuli ( 36 and $45 \mathrm{~mm}$ ) were significantly underestimated, and the two larger stimuli (63 and $72 \mathrm{~mm}$ ) were significantly overestimated $\left(x^{2}=14.89, \mathrm{df}=2, \mathrm{p}<.01\right)$. Analysis of the overall data shows highly significant differences between the three treatment or IS conditions $\left(x^{2}=142.58, \mathrm{df}=4, \mathrm{p}<.001\right)$.

Inspection of Fig. 1 shows that the number of smaller 
Table 1

Percentage of Smaller and Larger Reports of Series Stimuli

\begin{tabular}{cccc}
\hline $\begin{array}{c}\text { Interpolated } \\
\text { Stimulus }\end{array}$ & $\begin{array}{c}\text { Series } \\
\text { Stimuli }\end{array}$ & Smaller & Percent \\
\hline $18 \mathrm{~mm}$ & 36 & 28.6 & 71.4 \\
& 45 & 27.1 & 72.9 \\
& 54 & 17.1 & 82.9 \\
& 63 & 37.1 & 62.9 \\
$54 \mathrm{~mm}$ & 72 & 44.3 & 55.7 \\
\cline { 2 - 4 } & 36 & 74.3 & 25.7 \\
& 45 & 62.8 & 37.2 \\
& 54 & 42.9 & 57.1 \\
& 63 & 38.6 & 61.4 \\
& 72 & 37.1 & 62.9 \\
\hline \multirow{3}{*}{$\mathrm{mm}$} & 36 & 72.9 & 27.1 \\
& 45 & 78.6 & 21.4 \\
& 54 & 82.6 & 17.4 \\
& 63 & 87.1 & 12.9 \\
& 72 & 78.6 & 21.4 \\
\hline
\end{tabular}

judgments with IS of $90 \mathrm{~mm}$ is over twice as great as the number with IS of $18 \mathrm{~mm}$. The data for intermediate IS support the results for the small and large IS in that the per cents of smaller judgments with intermediate IS are above $50 \%$ for the two smaller stimuli and below $50 \%$ for the two larger stimuli. With all three IS, when IS is larger than series stimuli reports are predominantly smaller, and when IS is smaller than series stimuli reports are predominantly larger, thus showing size-contrast effects in expected directions.

\section{DISCUSSION}

Temporal or successive contrast characteristic of chromatic and luminance contrast is also found in perception of size; greater contrast effect is found with stimuli nearer the inducing IS stimulus than with stimuli farther from it as seen from Table 1. Thus with IS of $18 \mathrm{~mm}$ the percentage of larger reports is greater with the smaller series stimuli than with the larger, while with IS of $90 \mathrm{~mm}$ the percentage of smaller reports is greater with the larger series stimuli than with the smaller. A splitting effect is found with the intermediate IS which elicits a higher number of smaller reports with the smaller stimuli and a higher number of larger reports with the larger stimuli. The implications of these findings have a bearing on all psychophysical measurements; use of an intermediate standard or background such as a middle gray in visual work or the middle stimulus in weight lifting is often assumed to minimize contrast effects. As our results show, intermediate stimuli actually exert double contrast effects which are opposite in direction, raising the stimuli above and depressing those below the standard, as compared with the unidirectional effects of standard stimuli above or below the series stimuli. Usually the double effects of intermediate standards go unnoticed because comparisons are lacking with standards "outside" the series stimuli.

We also believe that these results have a bearing on figural aftereffects (FAE) though the conditions of stimulation are somewhat different in the two cases. In this study, series stimuli smaller than the IS fall within, and series stimuli larger than the IS fall outside, the area stimulated by the IS. These conditions are analogous to FAE conditions with effects similar to FAE. There is also some indication of the paradoxical distance effect (PDE) found with FAE in that with IS of $18 \mathrm{~mm}$ the maximum per cent larger occurs with $54 \mathrm{~mm}$ not with $36 \mathrm{~mm}$, and with IS of $90 \mathrm{~mm}$ the maximum per cent smaller is found with $63 \mathrm{~mm}$, not with $72 \mathrm{~mm}$. However, the occurrence of PDE under the conditions of this study should be checked by further experiments to establish its reliability beyond question. Certainly the smaller appearance of test figures inside the inspection figure and the larger appearance of figures outside the inspection figure point toward contrast mechanisms as at least in part responsible for FAE.

Finally, it should be noted there is a small time-order effect (TOE) in these results as shown by the greater percentage of larger reports for the middle stimulus of the series when IS is equal to it (54 mm, Table 1). However, it is not sufficiently great to account for the contrast effects found with intermediate IS.

\section{REFERENCES}

FLOCK, H. R., WILSON, A., \& POIZNER, S. Lightness matching for different visual routes through a compound scene. Perception \& Psychophysics, 1966, 1, 382-383.

HELSON, H., \& KOZAKI, A. Anchor effects using numerical estimates of simple dot patterns. Perception \& Psychophysics, 1968, 4, 163-164.

KOHLER, W., \& WALLACH, H. Figural after-effects: An investigation of visual processes. Proceedings of the American Philosophical Society, 1944, 88, 269-337.

\section{NOTES}

1. This work was supported, in part, by a grant from the National Research Council of Canada.

2. Address: Department of Psychology, University of Massachusetts, Amherst, Massachusetts 01002

3. Now at Keio University, Tokyo.

(Accepted for publication October 14, 1968.) 